\title{
CHARACTERIZATION OF ODOUR-ACTIVE VOLATILE COMPOUNDS OF ACEROLA WINE
}

\author{
J.A. PINO ${ }^{a *}$ and C.E. QuiJANo-CÉLIS ${ }^{b}$ \\ ${ }^{\mathrm{a}}$ Food Industry Research Institute, Carretera a Guatao km 3 1⁄2, Havana. Cuba \\ ${ }^{\mathrm{b}}$ Dept. of Química, Universidad de los Andes, Bogota. Colombia \\ (Received: 18 September 2018; accepted: 12 December 2018)
}

\begin{abstract}
The volatile compounds of acerola wine were isolated by headspace-solid phase microextraction (HS-SPME) and analysed by gas chromatography-flame ionization detector (GC-FID), gas chromatography-mass spectrometry (GC$\mathrm{MS}$ ), and gas chromatography-olfactometry (GC-O). The composition of acerola wine included 38 esters, 19 alcohols, 16 acids, 8 terpenes, 5 aldehydes, 5 ketones, 3 furans, and 8 miscellaneous compounds. The odour-active compounds were screened by application of the aroma extract dilution analysis and odour activity values. Nineteen odorants were considered as odour-active volatiles, from which methyl 2-methylbutanoate and 2-ethylhexan-1-ol were the most odour-active compounds.
\end{abstract}

Keywords: Malpighia glabra, acerola, wine volatiles, HS-SPME, GC-O, odour activity value

Acerola (Malpighia glabra L.) is a minor non-conventional fruit cultivated in many tropical zones. The fruit is considered as an excellent source of antioxidant and vitamin $\mathrm{C}$, and it is consumed fresh and used in food industry to produce juices, jams, and beverages (SoARES Filho \& Oliveira, 2003). Although the better-appreciated wines are made from grapes, other fruits could be utilized as raw materials for the manufacture of wines, such as acerola (Almeida et al., 2010, 2014; MinH, 2015). These wines have flavour and aroma characteristics of the original fruit and a good acceptance by the consumers. Although volatile compounds of acerola fruit have been studied to some extent (VENDRAminI \& TRUGO, 2000; Boulanger \& Crouzet, 2001; Pino \& Marbot, 2001), there is no information published to date on the volatiles of acerola wine.

Because the knowledge on the key odorants in the final product is the prerequisite for investigation on the influence of processing steps, the aim of the present study was to determine aroma profile and odour-active compounds of acerola wine by application of the aroma extract dilution analysis (AEDA) and odour activity values (OAV).

\section{Materials and methods}

Chemical standards ethyl propanoate (99\%), 3-methylbutan-1-ol (>99\%), methyl 2-methylbutanoate $(99 \%)$, ethyl butanoate $(99 \%)$, ethyl pyruvate $(98 \%), 2,3$-butanediol (98\%), ethyl 2-methylbutanoate (99\%), ethyl 3-methylbutanoate (98\%), 3-methylbutyl acetate (>99\%), 5-methyl-2-furfural (99\%), ethyl hexanoate ( $>99 \%)$, hexyl acetate $(99 \%)$, 2-ethylhexan-1-ol (99\%), allyl hexanoate (98\%), 2-phenylethanol (>99\%), ethyl

\footnotetext{
* To whom correspondence should be addressed. Phone: +53 72793956; e-mail: jpino@iiia.edu.cu
} 
3-phenylpropanoate (97\%), and methyl nonanoate $(98 \%)$ were purchased from SigmaAldrich (St. Louis, MO). A $\mathrm{C}_{8}-\mathrm{C}_{32} n$-alkane mixture, used for determination of Kovats retention indices were obtained from Sigma-Aldrich (St. Louis, MO). Absolute ethanol (>99.5\%), anhydrous citric acid (99\%), and sodium chloride (99.5\%) were purchased from Merck (Darmstadt, Germany).

Fresh and ripe acerola fruit $(25 \mathrm{~kg})$ were passed through a colloid mill. The pulp was added at $10 \%(\mathrm{w} / \mathrm{w})$ to a wort containing brown sugar $\left(190 \mathrm{~g} \mathrm{l}^{-1}\right)$, dibasic ammonium phosphate $\left(1 \mathrm{~g} \mathrm{l}^{-1}\right)$, and anhydrous citric acid $\left(2 \mathrm{~g} \mathrm{l}^{-1}\right)$. The wort was transferred into a stainless-steel tank for the fermentation using dried Saccharomyces cerevisiae yeasts $\left(1 \mathrm{~g} \mathrm{l}^{-1}\right.$, Fermipan Lefersa, Havana). Fermentation was performed in duplicate at controlled temperatures $\left(26 \pm 2{ }^{\circ} \mathrm{C}\right)$. After fermentation, the wine was racked by adding $0.5 \mathrm{~g} \mathrm{l}^{-1}$ sodium bisulphite and clarified by adding $0.1 \mathrm{~g} \mathrm{l}^{-1}$ kieselguhr. After 7 days, the wine was decanted and it was stored at $25^{\circ} \mathrm{C}$ for one month. The wines were packed in amber-coloured bottles of $0.75 \mathrm{l}$, which were sealed with cork. The wine was pasteurized by heating in a closed pan at $60{ }^{\circ} \mathrm{C}$ for $15 \mathrm{~min}$, cooled later in running water, and stored in refrigerator at $5{ }^{\circ} \mathrm{C}$ for a period of three months for posterior evaluation of its quality. The general compositions of juice and wine are given in Table 1.

Table 1. General composition of acerola juice and wine

\begin{tabular}{|c|c|}
\hline Juice composition & \\
\hline Soluble solids ( $\left.{ }^{\circ} \mathrm{Brix}\right)$ & $6.5 \pm 0.1$ \\
\hline Total acidity ( $\mathrm{g}^{-1}$ as anhydrous citric acid) & $7.0 \pm 0.6$ \\
\hline $\mathrm{pH}$ & $3.60 \pm 0.01$ \\
\hline Wine composition & \\
\hline Alcohol $(\% \mathrm{v} / \mathrm{v})$ & $11.40 \pm 0.01$ \\
\hline Total acidity ( $\mathrm{g}^{-1}$ as anhydrous citric acid) & $2.3 \pm 0.2$ \\
\hline $\mathrm{pH}$ & $3.12 \pm 0.01$ \\
\hline $\operatorname{Ash}\left(\mathrm{g}^{-1}\right)$ & $0.90 \pm 0.07$ \\
\hline
\end{tabular}

Brix value (method 932.12), total acidity (method 942.15), and $\mathrm{pH}$ (method 981.12) were determined in acerola juice, while alcohol (method 969.12), total acidity (method 962.12), and $\mathrm{pH}$ (method 960.19) in wine according to standard methods (AOAC, 2012).

Considering previous experiences (PINO \& QUERIS, 2010), the fibre used was coated with polydimethylsiloxane (PDMS), $100 \mu \mathrm{m}$ film thickness (Supelco, Bellefonte, PA). The fibre was thermally conditioned in accordance with the manufacturer's recommendations before first use. HS-SPME extractions were carried out by placing $8 \mathrm{ml}$ of wine, $1 \mathrm{~g}$ of $\mathrm{NaCl}$, and 20 $\mu \mathrm{l}$ of a methyl nonanoate internal standard solution $\left(20 \mathrm{mg} \mathrm{l}^{-1}\right.$ in ethanol) into a $15 \mathrm{ml}$-vial sealed with a PTFE/Silicone septum (Supelco, Bellefonte, PA). The mixture was carefully shaken and then left to equilibrate 15 min before the analysis. The results obtained from a previous work (PINO \& QUERIS, 2010) showed that $30{ }^{\circ} \mathrm{C}$ headspace sampling temperature and 30 min extraction time under stirring mode $\left(500 \mathrm{~min}^{-1}\right)$ resulted in the highest extraction efficiency. 
GC-FID analysis was performed on a Konik 4000A instrument (Konik, Barcelona) using hydrogen as the carrier gas at $1 \mathrm{ml} \mathrm{min}^{-1}$. Columns used were DB-Wax $(30 \mathrm{~m} \times 0.25$ $\mathrm{mm}, 0.25 \mu \mathrm{m}$ film thickness; J \& W Scientific, Folsom, CA) or DB- $5 \mathrm{~ms}(30 \mathrm{~m} \times 0.25 \mathrm{~mm}$, $0.25 \mu \mathrm{m}$ film thickness; J \& W Scientific, Folsom, CA), working with the following temperature program and conditions: $50{ }^{\circ} \mathrm{C}$ for $2 \mathrm{~min}$, ramp of $4{ }^{\circ} \mathrm{C} \mathrm{min}^{-1}$ up to $250{ }^{\circ} \mathrm{C}$; injector and detector temperatures $250^{\circ} \mathrm{C}$; detector FID; splitless injection (straight glass liner, $0.75 \mathrm{~mm}$ I.D.) for $2 \mathrm{~min}$. The relative quantities of the volatiles were expressed as peak area per cents in the GC-FID chromatogram. For some compounds (ethyl propanoate, 3-methylbutan-1-ol, methyl 2-methylbutanoate, ethyl butanoate, ethyl pyruvate, 2,3-butanediol, ethyl 2-methylbutanoate, ethyl 3-methylbutanoate, 3-methylbutyl acetate, 5-methyl-2-furfural, ethyl hexanoate, hexyl acetate, 2-ethylhexan-1-ol, allyl hexanoate, 2-phenylethanol, and ethyl 3-phenylpropanoate), chemical aroma standard mixtures were prepared in an $11 \%(\mathrm{v} / \mathrm{v})$ hydro-alcoholic solution to bracket the concentrations of each individual compound in acerola wine. Standard curves according to the internal standard method were created for these compounds. All analyses were replicated three times.

GC-MS analysis was made on a HP-6890 instrument gas chromatograph (HewlettPackard Co., Palo Alto, CA) interfaced with a HP-5973 mass-selective detector fitted with a DB-5ms column $(30 \mathrm{~m} \times 0.25 \mathrm{~mm}, 0.25 \mu \mathrm{m}$ film thickness; J \& W Scientific, Folsom, CA). Analytical conditions were the same as for GC-FID analyses: injector and transfer line temperatures $250^{\circ} \mathrm{C}$; carrier gas helium at $1 \mathrm{ml} \mathrm{min}^{-1}$; splitless injection (straight glass liner, $0.75 \mathrm{~mm}$ I.D.) for $2 \mathrm{~min}$. Mass spectra in the electron impact mode (EI-MS) were generated at $70 \mathrm{eV}$ and acquisition was performed in scanning mode (mass range $\mathrm{m} / \mathrm{z} 35-400 \mathrm{u}$ ). Identification of the constituents was based on comparison of the linear retention times with those of authentic samples, comparing their linear retention indices relative and on computer matching against commercial libraries (NIST 02, Wiley 275, Palisade 600, and Adams 2001) and FLAVORLIB homemade library mass spectra built up from pure substances and components of known essential oils. Some of the identifications were confirmed by the injection of the chemical standards into the GC-MS system. Linear retention indices of the compounds were calculated using an $n$-alkane series.

GC-O and AEDA analyses were performed on a HP-6890 gas chromatograph (HewlettPackard Co., Palo Alto, CA) converted for GC-O use by installing a glass effluent splitter and a glass sniffing port. The DB-5ms capillary column was connected to the glass effluent splitter with two deactivated fused silica tubing outlets of equal lengths $(50 \mathrm{~cm} \times 0.25 \mathrm{~mm})$ conducting the column effluent to the FID and to the sniffing port. Analyses were carried out using the analytical parameters described above for the $\mathrm{GC}$ analyses.

An approach of the AEDA technique developed for GC-O analysis of wine (MARTí et al., 2003) to estimate the sensory contribution of each odorant was used in the present study. It consists of carrying out successive dilutions of the acerola wine (steps 1:4) with a synthetic wine before the SPME. A mimic matrix was prepared by dissolving $2.3 \mathrm{~g}$ anhydrous citric acid and $114 \mathrm{ml}$ of absolute ethanol in a suitable amount of Milli-Q water to give one litre of solution. The $\mathrm{pH}$ value was adjusted to 3.1 with $0.1 \mathrm{~N} \mathrm{NaOH}$. To check the linearity of the HS-SPME procedure, a model mixture was prepared by adding some volatile compounds (ethyl propanoate, 3-methylbutan-1-ol, ethyl 3-methylbutanoate, 5-methyl-2-furfural, ethyl hexanoate, 2-ethylhexan-1-ol, 2-phenylethanol, and ethyl 3-phenylpropanoate), in a concentration level like acerola wine, to the synthetic wine solution.

The HS-SPME extracts from wine and its successive dilutions (1:4) were analysed using the methodology described earlier (MARTí et al., 2003). The flavour dilution (FD) factors 
obtained for each odorant in the AEDA is equal to the highest dilution in which the odorant can be perceived at the sniffing port by three assessors.

The odour detection thresholds in the mimic matrix described before were calculated as previously reported (PINO \& QUERIS, 2010). Calculation was made from the linear regression of percentage detection against log concentration. The $95 \%$ confidence limit calculated for the threshold values was used as a measure of error.

Quantitative descriptive aroma analysis was applied for evaluation of the wine, using a $10-\mathrm{cm}$ unstructured scale anchored at its left and right extremes by the terms 'none' (0) and 'extremely strong' (9), respectively. The sensory evaluations were generated by a panel of nine trained assessors aged between 22 and 35 years. In the first session, panellists generated descriptive terms for the wine; in the second and third, different aroma standards were presented and discussed by panellists. From these discussions, seven aroma terms (fruity, sweet, winey, fermentation, caramel, flowery, and vinegar) were selected for further descriptive analysis. In the fourth and fifth sessions, the wine was evaluated in duplicate using the 10-point interval scale mentioned above. The reference materials for aroma descriptors were as follow: fruity ( $7 \mu \mathrm{g}^{-1}$ aqueous solution of ethyl 2-methylbutanoate), sweet ( $1 \mathrm{ml}$ liquid caramel in $100 \mathrm{ml} \mathrm{10 \%}$ ethanol-water solution), winey (5 $\mathrm{ml}$ of sherry wine in $100 \mathrm{ml} \mathrm{10 \%}$ ethanol-water solution), fermentation ( $0.5 \mathrm{~g}$ dry yeast in $100 \mathrm{ml}$ sugar solution after overnight), caramel ( $1 \mathrm{mg} \mathrm{ml}^{-1}$ aqueous solution of maltol), flowery ( $1 \mathrm{mg} \mathrm{l}^{-1}$ aqueous solution of 2-phenylethanol), and vinegar $\left(5 \mathrm{mg} \mathrm{ml}^{-1}\right.$ aqueous solution of acetic acid). Orthonasal evaluations were performed in coded cylindrical glass vessels $(7 \mathrm{~cm} \times 3.5$ $\mathrm{cm}$ ) containing $20 \mathrm{ml}$ of wine.

\section{Results and discussion}

Although some studies of wines made from tropical fruits reported the use of direct sampling SPME (SELLi et al., 2004; KAFKAS et al., 2006), headspace sampling was selected for this study to avoid interferences from nonvolatile matrix components and to increase fibre lifetime. As can be seen in Table 2, a total of 102 volatile compounds were identified in the acerola wine, in which esters were found to be the most abundant volatile constituents (38 compounds), as they accounted for the largest proportion of the total aroma. Also, 19 alcohols, 16 acids, 8 terpenes, 5 aldehydes, 5 ketones, 3 furans, and other 8 of different chemical nature were identified in the acerola wine.

Table 2. Volatiles identified in acerola wine

\begin{tabular}{lcccc}
\hline Compound & LRI $_{\mathrm{a}}{ }^{\mathrm{a}}$ & LRI $_{\mathrm{p}}{ }^{\mathrm{a}}$ & Identity $^{\mathrm{b}}$ & \multicolumn{2}{c}{ Area $\%^{\%}$} \\
\hline Ethanol & 537 & 932 & $\mathrm{~A}$ & 2.0 \\
2-Methylpropan-1-ol & 625 & 1108 & $\mathrm{~A}$ & 0.8 \\
Acetic acid & 645 & 1450 & $\mathrm{~A}$ & 4.2 \\
Butan-1-ol & 669 & 1150 & $\mathrm{~A}$ & 0.4 \\
Pentan-2-one & 688 & 983 & $\mathrm{~A}$ & 0.6 \\
1-Hydroxypropan-2-one & 694 & 1300 & $\mathrm{~B}$ & $\mathrm{~A}$ \\
Pentan-3-one & 703 & 984 & $\mathrm{~A}$ & $<0.1$ \\
Ethyl propanoate & 717 & 925 & & 0.3 \\
\hline
\end{tabular}


Table 2 (continued)

\begin{tabular}{|c|c|c|c|c|}
\hline Compound & $\operatorname{LRI}_{\mathrm{a}}^{\mathrm{a}}$ & $\mathrm{LRI}_{\mathrm{p}}^{\mathrm{a}}$ & Identity $^{\mathrm{b}}$ & Area \% \\
\hline Propyl acetate & 728 & 977 & A & 0.1 \\
\hline 1,1-Diethoxyethane & 726 & 889 & A & 0.1 \\
\hline 3-Methylbutan-1-ol & 741 & 1212 & A & 13.1 \\
\hline 2-Methylbutan-1-ol & 742 & 1210 & A & 3.6 \\
\hline Dimethyl disulfide & 745 & 1066 & A & $<0.1$ \\
\hline Methyl 2-methylbutanoate & 772 & 1015 & A & 2.6 \\
\hline 2-Methylpropanoic acid & 785 & 1580 & A & $<0.1$ \\
\hline 2-Methylpropyl acetate & 788 & 1022 & A & 0.5 \\
\hline Ethyl butanoate & 805 & 1044 & A & 0.5 \\
\hline Ethyl pyruvate & 807 & 1242 & A & 0.3 \\
\hline 2,3-Butanediol & 810 & 1543 & A & 1.7 \\
\hline Ethyl 2-hydroxypropanoate & 815 & 1358 & A & 0.1 \\
\hline 2-Furfural & 836 & 1165 & A & 11.6 \\
\hline 3-Methylbutanoic acid & 838 & 1022 & A & $<0.1$ \\
\hline Ethyl 2-methylbutanoate & 850 & 1050 & A & 0.8 \\
\hline (E)-3-Hexen-1-ol & 854 & 1369 & A & $<0.1$ \\
\hline Ethyl 3-methylbutanoate & 857 & 1056 & A & 0.9 \\
\hline (Z)-3-Hexen-1-ol & 859 & 1391 & A & 0.3 \\
\hline 1,1-Diethoxy-2-methylpropane & 861 & 969 & B & 0.2 \\
\hline Hexan-1-ol & 871 & 1360 & A & 0.8 \\
\hline 3-Methylbutyl acetate & 881 & 1195 & A & 1.3 \\
\hline 2-Methylbutyl acetate & 884 & 1112 & A & 0.4 \\
\hline Heptan-2-one & 892 & 1170 & A & $<0.1$ \\
\hline Ethyl pentanoate & 901 & 1131 & A & 0.2 \\
\hline$\gamma$-Butyrolactone & 918 & 1647 & B & $<0.1$ \\
\hline$\alpha$-Pinene & 940 & 1032 & A & $<0.1$ \\
\hline 5-Methyl-2-furfural & 962 & 1560 & A & 12.2 \\
\hline Ethyl 2-hydroxy-3-methylbutanoate & 965 & 1427 & B & 0.7 \\
\hline Heptan-1-ol & 967 & 1310 & A & $<0.1$ \\
\hline$\beta$-Pinene & 977 & 1116 & A & $<0.1$ \\
\hline 1-Octen-3-ol & 982 & 1394 & A & 0.3 \\
\hline Octan-3-one & 984 & 1244 & A & 0.1 \\
\hline Hexanoic acid & 988 & 1850 & A & 0.2 \\
\hline Octan-3-ol & 991 & 1399 & A & 0.1 \\
\hline Ethyl hexanoate & 998 & 1229 & A & 4.2 \\
\hline Octanal & 999 & 1280 & A & 0.5 \\
\hline Ethyl (Z)-3-hexenoate & 1002 & 1292 & B & 0.2 \\
\hline Hexyl acetate & 1009 & 1276 & A & 0.1 \\
\hline 1,4-Cineole & 1016 & 1169 & A & 0.1 \\
\hline
\end{tabular}


Table 2 (continued)

\begin{tabular}{|c|c|c|c|c|}
\hline Compound & $\mathrm{LRI}_{\mathrm{a}}^{\mathrm{a}}$ & $\mathrm{LRI}_{\mathrm{p}}^{\mathrm{a}}$ & Identity $^{\mathrm{b}}$ & Area \% \\
\hline 4-Methyl-5-vinylthiazole & 1021 & 1512 & B & $<0.1$ \\
\hline Limonene & 1029 & 1178 & A & $<0.1$ \\
\hline 2-Ethylhexan-1-ol & 1032 & 1380 & A & 0.6 \\
\hline Salicylaldehyde & 1043 & 1663 & A & $<0.1$ \\
\hline Ethyl 2-furoate & 1047 & 1627 & A & 0.2 \\
\hline Ethyl 2-hydroxy-4-methylpentanoate & 1060 & 1547 & B & 0.8 \\
\hline 3-Methylbutyl lactate & 1065 & 1572 & A & $<0.1$ \\
\hline Octan-1-ol & 1068 & 1553 & A & 0.1 \\
\hline Allyl hexanoate & 1083 & 1371 & A & 0.1 \\
\hline Heptanoic acid & 1085 & 1966 & A & 0.1 \\
\hline Nonan-2-one & 1091 & 1441 & A & 0.6 \\
\hline Ethyl heptanoate & 1098 & 1337 & A & 0.5 \\
\hline Nonan-2-ol & 1100 & 1532 & B & $<0.1$ \\
\hline Nonanal & 1103 & 1385 & A & 0.2 \\
\hline 2-Phenylethanol & 1107 & 1873 & A & 3.8 \\
\hline Methyl octanoate & 1127 & 1386 & A & $<0.1$ \\
\hline 2-Ethylhexanoic acid & 1128 & 1969 & A & $<0.1$ \\
\hline 2-Methylpropyl hexanoate & 1150 & 1351 & A & $<0.1$ \\
\hline Nerol oxide & 1158 & 1467 & B & $<0.1$ \\
\hline Nonan-1-ol & 1169 & 1668 & A & 0.1 \\
\hline Ethyl benzoate & 1173 & 1644 & A & 0.1 \\
\hline Diethyl succinate & 1179 & 1687 & A & 12.2 \\
\hline Octanoic acid & 1183 & 2050 & A & 0.6 \\
\hline$\alpha$-Terpineol & 1189 & 1694 & A & $<0.1$ \\
\hline Ethyl octanoate & 1197 & 1442 & A & 5.8 \\
\hline Decanal & 1204 & 1502 & A & 0.1 \\
\hline$\beta$-Cyclocitral & 1220 & - & $\mathrm{C}$ & $<0.1$ \\
\hline Ethyl 2-phenylacetate & 1245 & 1782 & A & 0.1 \\
\hline 3-Methylbutyl hexanoate & 1254 & 1733 & A & $<0.1$ \\
\hline 2-Phenylethyl acetate & 1259 & 1825 & A & 0.1 \\
\hline Nonanoic acid & 1297 & 2168 & A & 0.3 \\
\hline Ethyl nonanoate & 1320 & 1520 & A & 0.3 \\
\hline Methyl anthranilate & 1337 & 2188 & A & $<0.1$ \\
\hline Ethyl 3-phenylpropanoate & 1353 & 1900 & A & $<0.1$ \\
\hline Decanoic acid & 1379 & 2279 & A & 0.3 \\
\hline Ethyl $(E)$-4-decenoate & 1383 & 1680 & A & 0.1 \\
\hline Ethyl $(E)-9$-decenoate & 1389 & 1712 & A & 0.5 \\
\hline Ethyl decanoate & 1396 & 1642 & A & 1.9 \\
\hline Dodecanal & 1410 & 1729 & A & $<0.1$ \\
\hline
\end{tabular}


Table 2 (continued)

\begin{tabular}{|c|c|c|c|c|}
\hline Compound & $\operatorname{LRI}_{\mathrm{a}}{ }^{\mathrm{a}}$ & $\operatorname{LRI}_{\mathrm{p}}{ }^{\mathrm{a}}$ & Identity $^{\mathrm{b}}$ & Area \% \\
\hline Ethyl anthranilate & 1416 & 2232 & A & 0.1 \\
\hline (E)-Geranyl acetone & 1455 & 1803 & B & $<0.1$ \\
\hline Ethyl $(E)$-cinnamate & 1466 & 2149 & A & $<0.1$ \\
\hline Dodecanoic acid & 1569 & 2514 & A & 0.5 \\
\hline Ethyl dodecanoate & 1595 & 1838 & A & $<0.1$ \\
\hline$n$-Hexadecane & 1600 & 1600 & A & $<0.1$ \\
\hline Tridecanoic acid & 1660 & 1924 & A & 0.1 \\
\hline$n$-Heptadecane & 1700 & 1700 & A & $<0.1$ \\
\hline Tetradecanoic acid & 1779 & 2656 & A & 1.0 \\
\hline Ethyl tetradecanoate & 1796 & 2044 & A & $<0.1$ \\
\hline Pentadecanoic acid & 1868 & 2819 & A & 0.8 \\
\hline (Z)-9-Hexadecenoic acid & 1950 & 2960 & A & 0.2 \\
\hline Hexadecanoic acid & 1960 & 2900 & A & 0.7 \\
\hline Heptadecan-1-ol & 1986 & 2482 & A & 0.1 \\
\hline (Z)-9-Octadecenoic acid & 2141 & 3172 & A & 0.1 \\
\hline Octadecanoic acid & 2200 & 3092 & A & 0.3 \\
\hline
\end{tabular}

a: LRI and LRI : Experimental linear retention index on capillary columns DB-5ms and DB-Wax; ${ }^{\text {b }}$ The reliability of the identification proposal is indicated by the following: A: mass spectrum and RI agreed with standards; B: mass spectrum and RI agreed with database or literature; C: mass spectrum agreed with mass spectral database

Among the esters, diethyl succinate, ethyl octanoate, and ethyl hexanoate were the major components in the acerola wine. The detected volatile esters can originate from alcoholic fermentation by yeast (ETIEVANT, 1991).

The volatile compounds extracted by HS-SPME were evaluated using AEDA and OAV to find the most potent odorants. The results of the AEDA and OAV studies are given in Table 3 , in which odour zones are arranged following their elution order from the nonpolar column. The AEDA yielded 20 odour regions with flavour dilution (FD) factors $\geq 32$. A great variety of odour qualities, such as fruity, sweet, caramel, or flowery were detected, but no single odorant resembled the acerola wine aroma. Sniffing of the serial dilutions revealed the highest FD factors for methyl 2-methylbutanoate (fruity), 2-ethylhexan-1-ol (sweet, slightly flowery), allyl hexanoate (fruity, sweet), and ethyl octanoate (fruity).

Two of the compounds identified as potentially relevant by AEDA were found with $\mathrm{OAVs}<1$ and therefore, they should not contribute to acerola wine aroma. The possibly key compound obtained with the odour activity approach is a refinement of that provided by the AEDA, and corrects some of the limits of the AEDA technique.

Odour activity values are a good means to correlate quantitative data with the volatility of a compound from the respective matrix (SCHIEBERLE, 1995). However, it is necessary that the odour threshold of the compound should be determined in a matrix as close as possible to the food itself. For this reason, the odour thresholds for the components with higher DF were determined in a mimic matrix, representing the acerola wine (Table 3). By far, the highest values were calculated for methyl 2-methylbutanoate and 2-ethylhexan-1-ol. However, the results suggested that 18 compounds should additionally contribute to the characteristic 
aroma of acerola wine, because their concentrations clearly exceeded their odour thresholds in water/ethanol. Relatively high odour activity values were also calculated for ethyl octanoate, ethyl hexanoate, ethyl 3-methylbutanoate, 5-methyl-2-furfural, and nonanal with OAVs ranged 9-101. With odour activity values between 1 and 4, ethanol, ethyl propanoate, 3-methylbutan-1-ol, ethyl pyruvate, 2,3-butanediol, 3-methylbutyl acetate, hexyl acetate, 2-phenylethanol, and ethyl 3-phenylpropanoate should also contribute to acerola wine aroma.

Table 3. Most odour-active volatile compounds identified in acerola wine

\begin{tabular}{|c|c|c|c|c|c|}
\hline Compound & $\begin{array}{l}\text { Content } \\
\left(\mathrm{mg} \mathrm{l}^{-1}\right)\end{array}$ & Odour quality $^{\mathrm{a}}$ & $\begin{array}{c}\text { Odour } \\
\text { threshold } \\
\left(\mu \mathrm{g} \mathrm{l}^{-1}\right)\end{array}$ & FD factor & $\mathrm{OAV}^{\mathrm{b}}$ \\
\hline Ethanol & 114000 & alcohol & $24900^{\mathrm{c}}$ & - & 5 \\
\hline Ethyl propanoate & 0.017 & rum-like, pineapple & 10 & 64 & 2 \\
\hline 3-Methylbutan-1-ol & 0.700 & fermented, fruity & 280 & 64 & 2 \\
\hline 2-Methylbutan-1-ol & 0.190 & fermented, fruity & 300 & 64 & $<1$ \\
\hline Methyl 2-methylbutanoate & 0.141 & fruity & 0.5 & 512 & 281 \\
\hline Ethyl butanoate & 0.028 & fruity, sweet & 20 & 32 & 1 \\
\hline Ethyl pyruvate & 0.017 & caramel & 5 & 64 & 3 \\
\hline 2,3-Butanediol & 0.091 & fruity & 30 & 64 & 3 \\
\hline Ethyl 2-methylbutanoate & 0.042 & fruity, green & 18 & 64 & 2 \\
\hline Ethyl 3-methylbutanoate & 0.046 & fruity, berry-like & 3 & 128 & 15 \\
\hline 3-Methylbutyl acetate & 0.070 & fruity, banana & 30 & 32 & 2 \\
\hline 5-Methyl-2-furfural & 0.650 & caramel-like & 60 & 128 & 11 \\
\hline Ethyl hexanoate & 0.225 & fruity, winey & 14 & 128 & 16 \\
\hline Hexyl acetate & 0.005 & fruity & 2 & 64 & 2 \\
\hline 2-Ethylhexan-1-ol & 0.030 & sweet, slightly flowery & 0.3 & 512 & 101 \\
\hline Allyl hexanoate & 0.005 & fruity, sweet & 0.1 & 256 & 47 \\
\hline Nonanal & 0.009 & orange-like & 1 & 32 & 9 \\
\hline Diethyl succinate & 0.310 & winey & 1250 & 32 & $<1$ \\
\hline 2-Phenylethanol & 0.200 & flowery, sweet & 140 & 32 & 1 \\
\hline Ethyl octanoate & 0.310 & fruity & 5 & 256 & 62 \\
\hline Ethyl 3-phenylpropanoate & 0.001 & flowery & 0.65 & 64 & 2 \\
\hline
\end{tabular}

${ }^{a}$ : Odour quality perceived at the sniffing port; ${ }^{\text {b }}$ : Odour-activity values were calculated by dividing the concentrations by the respective odour threshold; ${ }^{c}$ : The odour activity value for ethanol was calculated by dividing its concentration by its odour threshold in water.

Concerning similarities between HS-SPME-GC-O and OAV strategies, HS-SPMEGC-O has been very effective, since with a very small effort, it has been able to identify the most important odorants, according to the OAV criteria. Only ethanol ranked high according to OAV did not have a high GC-O score. 
Figure 1 shows the mean intensity ratings for acerola wine plotted on a spider graph using six descriptors. In this diagram, the centre of the figure represents low intensity with respect to each descriptor, increasing to an intensity of nine at the ends of the axes. As can be seen, the fruity, sweet, flowery, and caramel series were those that contributed most markedly to the aroma profile. The fruity series was probably influenced mainly by allyl hexanoate, methyl 2-methylbutanoate, ethyl octanoate, and ethyl hexanoate. The sweet series had 2-ethylhexan-1-ol and allyl hexanoate as its main contributors, followed by ethyl butanoate and 2-phenylethanol. In the flowery series, the aroma contribution of ethyl 3-phenylpropanoate and 2-phenylethanol must also be the highest. The caramel series had 5-methyl-2-furfural and ethyl pyruvate as its main contributors. Other series with lesser impact were winey, fermentation, and vinegar.

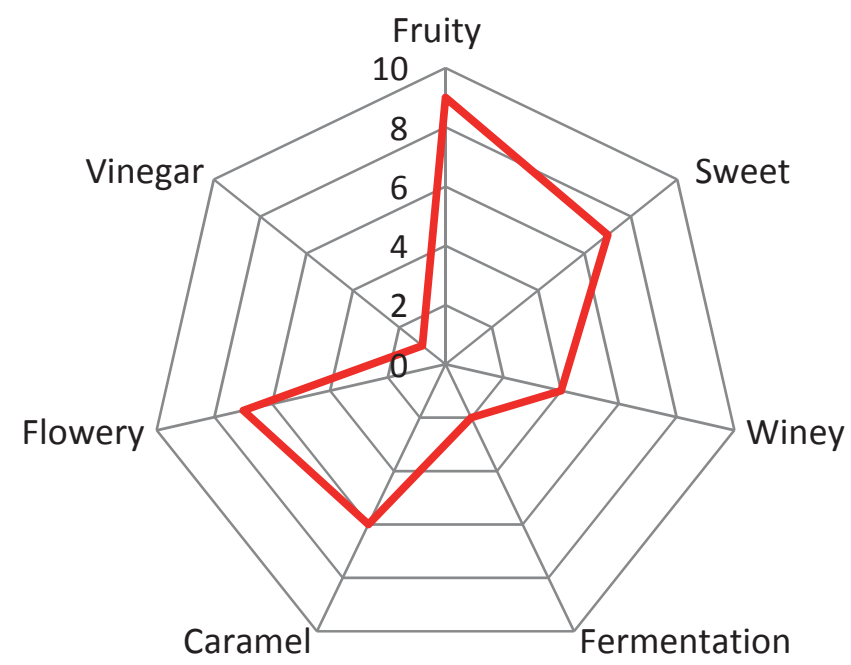

Fig. 1. Aroma sensory profiles of acerola wine

Sensory studies need to be done to determine the definite contribution of these volatile compounds to acerola wine, including model and omission experiments.

\section{Conclusions}

The study has revealed potent odorants that are responsible for the overall flavour of the acerola wine. Results of the AEDA and OAVs studies showed that odour profile of acerola wine was mainly caused by nineteen odorants, from which methyl 2-methylbutanoate and 2-ethylhexan-1-ol were the most odour-active compounds. These compounds are suitable indicators of the objective quality of the acerola wine. The high concordance of results between the OAV approach and HS-SPME-GC-O suggests that the latter has a great potential as a fast and simple tool to control and assess aroma quality of acerola wine. 


\section{References}

Almeida, S.S., Narain, N., Souza, R.R. \& Santana, J.C.C. (2010): Optimization of processing conditions for wine production from acerola (Malpighia glabra L.). Acta Hort., 864, 471-478.

Almeida, S.S., Alves, W.A.L., De Araújo, S.A., Santana, J.C.C., Narain, N. \& De Souza, R.R. (2014): Use of simulated annealing in standardization and optimization of the acerola wine production. Food Sci. Tech.Brazil, 34(2), 292-297.

AOAC (2012): Official Methods of Analysis, $19^{\text {th }}$ ed. Association of Official Analytical Chemist. AOAC International, Washington DC.

Boulanger, R. \& Crouzet, J. (2001): Identification of the aroma components of acerola (Malpighia glabra L.): Free and bound flavor compounds. Food Chem., 74, 209-216.

Etievant, P.X. (1991): Wine. -in: MaArse, H. (Ed.) Volatile compounds in food and beverages. Marcel Dekker, New York, pp. 483-546.

Kafkas, E., Cabaroglu, T., Selli, S., Bozdof̂an, A., KürkçüoĞlu, M., Paydaş, S. \& Bașer, K.H.C. (2006): Identification of volatile aroma compounds of strawberry wine using solid-phase microextraction techniques coupled with gas chromatography-mass spectrometry. Flavour Frag. J., 21, 68-71

Martí, M.P., Mestres, M., Sala, C., Busto, O. \& Guasch, J. (2003): Solid-phase microextraction and gas chromatography olfactometry analysis of successively diluted samples. A new approach of the aroma extract dilution analysis applied to the characterization of wine aroma. J. Agr. Food Chem., 51, 7861-7865.

Minh, N.P. (2015): Favorable conditions for fermentation of acerola wine. Int. J. Pure App. Biosci., 3(2), 81-88.

Pino, J.A. \& Marbot, R. (2001): Volatile flavor constituents of acerola (Malpighia emarginata DC.) fruit. J. Agr. Food Chem., 49, 5880-5882.

PINO, J.A. \& Queris, O. (2010): Analysis of volatile compounds of pineapple wine using solid-phase microextraction techniques. Food Chem., 122, 1241-1246.

Schieberle, P. (1995): Recent developments in methods for analysis of flavor compounds and their precursors. -in: Goankar, A (Ed.) Characterization of food: Emerging methods. Elsevier, Amsterdam, The Netherlands, pp. 403-431.

Selli, S., KürkçüoĜlu, M., Kafkas, E., Cabaroglu, T., Demirci, B., Bașer, K.H.C. \& Canbas, A. (2004): Volatile flavour components of mandarin wine obtained from clementines (Citrus reticulata Blanco) extracted by solid-phase microextraction. Flavour Frag. J., 19, 413-416.

Soares Filho, W.S. \& Oliveira, J.R.P. (2003): Introdução. -in: Ritzinger, R., Kobayashi, A.K. \& Oliveira, J.R.P. (Eds) A cultura da aceroleira. Embrapa Mandioca e Fruticultura, Cruz das Almas, BA, p. 198.

Vendramini, A.L. \& Trugo, L.C. (2000): Chemical composition of acerola fruit (Malpighia punicifolia L.) at three stages of maturity. Food Chem., 71, 195-198. 